\title{
Shorter commutes, but for whom? Comparing the distributional effects of Bus Rapid Transit on commute times in Cape Town, South Africa, and Barranquilla, Colombia
}

\author{
Manuel Santana Palacios (corresponding \\ author) \\ University of California, Berkeley \\ manuel.santana@berkeley.edu
}

\author{
Lisa Rayle \\ University of California, Berkeley \\ Irayle@gmail.com
}

\begin{abstract}
Bus rapid transit has become an increasingly popular investment in cities in the Global South, where policy discourse often positions BRT as a pro-poor investment. Planners usually expect BRT to reduce commute times in urban areas, particularly for economically disadvantaged populations, thus reducing mobility gaps between transit users across different socioeconomic population groups. Despite increased interest in BRT, there is surprisingly limited research testing these assumptions. Using data from a retrospective survey administered in Barranquilla, Colombia, and Cape Town, South Africa, we investigated whether BRT contributes to reducing commute time gaps between socioeconomic populations. Our comparative and distributional analyses indicate that, while BRT narrowed the gap in commute times in Cape Town, it did not contribute to closing the gap in Barranquilla. We argue that this contradiction may, in part, be explained by the degree to which BRT route configuration responded to the urban form and pre-BRT transit conditions in each city-two factors often overlooked in academic literature and discussions surrounding BRT planning. We close by providing policy recommendations that promote more equitable planning practices and recognize the links between transport and land uses in the Global South urban context.
\end{abstract}

\section{Article history:}

Received: October 11, 2020

Received in revised form:

February 4, 2021

Accepted: February 4, 2021

Available online: June 18, 2021

\section{Introduction}

Bus rapid transit (BRT) has become an increasingly popular investment worldwide. BRT systems can provide travel time advantages through a bundle of high-standard design elements that enable buses to increase speeds and provide passengers streamlined access to stations and vehicles. BRT buses operate on segregated busways, or trunk corridors, allowing them to reach significantly higher speeds (Cervero, 2013; Munoz \& Paget-Seekins, 2016). The median-location of BRT corridors reduces conflicts with turning vehicles and on-street parking, reducing delays (Cervero, 2013). Furthermore, design elements, such as the use of smart-card-based off-board fare collection systems and platform-level boarding, offer passengers quicker access to transit (Cervero, 2013). Thus, like rail systems, BRT can deliver significant travel time savings to commuters; however, BRT is faster to build at a fraction of the cost (Munoz \& Paget-Seekins, 2016; Venter, Jennings, Hidalgo, \& Valderrama Pineda, 2017).

Because of these travel time and cost advantages, BRT is often positioned as an equitable transit

Copyright 2021 Manuel Santana Palacios \& Lisa Rayle

http://dx.doi.org/10.5198/jtlu.2021.1907

ISSN: 1938-7849 | Licensed under the Creative Commons Attribution - Noncommercial License 4.0

The Journal of Transport and Land Use is the official journal of the World Society for Transport and Land Use (WSTLUR) and is published and sponsored by the University of Minnesota Center for Transportation Studies. 
option in policy discourse, particularly in cities in the Global South. Shaped in part by broader policy agendas and some road infrastructure attributes, most BRT systems are designed following Bogotås BRT trunk-feeder system (Cervero, 2013; Montero, 2020; Silva Ardila, 2020). These BRT trunk-feeder systems consist of large-size buses operating on trunk-only bus corridors, often placed on pre-existing arterial road infrastructure, functioning as the system's backbone. BRT corridors are complemented by feeder services made up of mid-size buses circulating in mixed-traffic lanes. These feeder services extend the geographical reach of BRT to less dense and sprawling peripheral neighborhoods whose street networks are not suitable for trunk corridor construction. Examples of trunk-feeder BRT systems can be found in Seoul, Cape Town, Johannesburg, and many Latin American cities, including Barranquilla, Cali, Rio de Janeiro, and Lima.

BRT roll-out in these cities has often been promoted as a means for restructuring pre-existing, largely privately-run, loosely regulated or unregulated, and inefficient shared "private transit" and "paratransit" services (Ardila-Gómez, 2008; Munoz \& Paget-Seekins, 2016). Private transit services consist of mid-to large-size buses, often managed by private companies regulated by the state; paratransit is defined as a subset of private transit consisting of smaller vehicles that are typically more loosely regulated or illegal (Santana Palacios et al., 2020). Because private transit services operate in often-congested mixed-traffic lanes, the higher speeds enabled by BRT corridors may result in large travel time savings for commuters who switched to BRT services. Moreover, BRT has the potential to enable commute time savings for economically disadvantaged population groups in urban contexts where BRT reaches peripheral areas through feeder services through its seamless integration with trunk corridors. Although the replacement of direct-service private transit routes with trunk-feeder BRT systems may induce more transfers for those living in peripheral areas, higher travel speeds on BRT trunk corridors should, in theory, compensate for the induced transferring times, reducing travel time overall. Based on this information, planners policymakers expect that investment in BRT will benefit economically disadvantaged groups (Venter et al., 2017).

Investing in BRT to reduce economically disadvantaged groups' commute times is an important policy objective for multiple reasons. One main reason is that economically disadvantaged populations in Global South cities often commute for considerably longer distances than their non-economically disadvantaged counterparts (Vasconcellos, 2014). Furthermore, the growing body of literature connecting transport and health outcomes suggests that longer commute times are associated with higher stress levels (Gottholmseder, Nowotny, Pruckner, \& Theurl, 2009; Evans \& Wener, 2006) and lesser life satisfaction (Chatterjee et al., 2020; Hilbrecht, Smale, \& Mock, 2014). Also, designing BRT systems that benefit disadvantaged populations may help reduce commute time and employment accessibility inequalities, consistent with moral principles of distributive justice (also referred to as equity in the literature) promoted by urban planners and transport scholars alike (Pereira, Schwanen, \& Banister, 2017; Venter et al., 2017).

Despite policymakers' interest and investment in BRT as a pro-poor public transit solution, few studies test whether BRT reduces commute time gaps between different socioeconomic groups in urban areas or what factors, including urban form, pre-existing transit conditions, and BRT network configuration, may contribute to the distribution of the change in commute times across these groups. Drawing primarily on a retrospective intercept survey administered in Cape Town, South Africa, and Barranquilla, Colombia, five years after the introduction of new BRT systems in each city, we analyzed changes in commute times of different groups of residents and BRT users and compared our results. Since we wanted to understand the first order (or direct) effects of BRT on commute times, our focus in this paper is on residents who did not change home or work location (hereafter referred to as "nonmovers"). Our comparative analysis provides diverging results that, when triangulated with data on 
pre-BRT transit conditions and urban form characteristics, contribute to policy debates and academic discussions surrounding BRT and transport justice in the Global South.

\section{$2 \quad$ Literature review}

Empirical evidence indicates BRT delivers multiple benefits to its users, including reductions in air pollution (Bel \& Holst, 2018; Hidalgo, Pereira, Estupiñán, \& Jiménez, 2013; Nugroho, Fujiwara, \& Zhang, 2011) and reductions in death and injury from traffic accidents (Duduta, Adriazola, Hidalgo, Lindau, \& Jaffe, 2012; Hidalgo et al., 2013). Other studies suggest that BRT deployment is associated with positive effects on land values and development patterns (Cervero \& Kang, 2011; Rodriguez \& Targa, 2004; Rodriguez, Vergal-Trovar, \& Camargo, 2016). Despite the empirical evidence detailing these benefits, differential effects across user groups are underrepresented in academic literature (Venter et al., 2017). Moreover, studies that test whether BRT helps reduce inequalities in commute times between these groups are surprisingly limited.

The vast majority of empirical studies that focus on travel times suggest that the average travel time reductions enabled by BRT across populations are significant; however, the question of distributive justice (also referred to as equity in transport policy discussion) is rarely addressed. For example, Ernest's (2005) assessment of Jakarta's first BRT corridor suggests that users reduced their travel time by 59 minutes over the corridor's whole length at peak hour. Alpkokin and Ergun (2012) found that Istanbul's BRT corridor reduced travel times by about 50 minutes. This body of literature, which focuses solely on travel times, paints a reassuring picture. Nevertheless, studies based primarily on BRT corridors (or trunk services) fail to report whether they account for out-of-vehicle travel times and overlook the following fundamental questions: 1) How are travel time savings from trunk-feeder BRT systems distributed among different population groups? 2) Which socioeconomic groups benefit most from investments in trunk-feeder BRT systems? and 3) How might some BRT route configurations privilege some groups over others?

Most of the scholarship that examines BRT deployment in the context of transport equity in the Global South focuses on accessibility benefits. These studies rely primarily on cross-sectional analyses to identify underserved areas (see, for instance, Delmelle \& Casas, 2012, or Scholl et al., 2016). Although coverage issues are not unimportant distributive justice issues, these studies fail to address the questions above. Some scholars, however, have recently capitalized on data that captures employment spatial data and network changes over time to assess changes in job accessibility induced by travel time savings enabled by BRT. One influential study is conducted by Pereira, Bansiter, Schwanen, and Wessel (2019), who found that Rio de Janeiro's BRT employment accessibility benefits are skewed towards middle- and high-income areas. Oviedo, Scholl, Innao, and Pedraza (2019) report similar findings in their study of Lima's BRT. This research sheds some light on the distributional effects of benefits from BRT; however, questions about the influence of BRT design and urban form on the distribution of such benefits remain largely underexplored.

Moreover, research that relies primarily on multiple cross-sections where effects are confounded by multiple factors, such as home and workplace relocation patterns, has yielded inconclusive results about the effects of BRT on different population groups. Furthermore, most studies focus on a single intervention, which prevents researchers from making generalizations. For example, using survey data provided by Bogotâs BRT agency, Hidalgo and Yepes (2005) assessed travel time changes enabled by Bogotâs TransMilenio. The authors found that TransMilenio delivered greater travel time savings for low-income than middle-income passengers. However, in another study on Bogotás TransMilenio, Lleras (2003) found that while those using only trunk services reduced their travel times, passengers who require one 
or more transfers experienced an increase in travel times.

A subsequent study conducted by Scholl et al. (2016) examined the effects of Cali's and Lima's BRT systems on travel times. Their research, which relied on GIS network analysis tools, also generated mixed results. Their analysis indicates that the lowest- and highest-income areas in Cali benefited with greater travel time savings than middle-income groups. In Lima, travel time savings associated with BRT deployment could be up to 34 minutes in some low-middle-income zones. In comparison, maximum savings in poor and very poor areas were 32 and 28 minutes, respectively, versus an average city-wide seven-minute decline. The authors noted that one possible explanation for their diverging results is the difference in BRT coverage, highlighting the challenges of reaching settlements in hilly and peripheral areas.

Gomez-Lobo (2020) provides some insights into the potential effects of restructuring private transit through trunk-feeder BRT systems on intra-urban travel in a more recent study. Using a multi-city and longitudinal data set, he found that cities that deployed BRT in Colombia experienced a more considerable decline in demand for public and private transit than similar cities that did not opt for such investment. By triangulating these primary findings with secondary data sources, the author posited that the BRT corridors in mid-sized cities tend to be relatively short and do not sufficiently reduce travel time to compensate for the more prolonged walking and waiting times induced by BRT. However, despite this significant contribution of his work, Gomez-Lobo's work does not provide empirical evidence on whether BRT helped reduce inequalities in commute times.

Gomez-Lobo's conjecture is expanded when placed in conversation with other recent scholarship. For example, drawing from in-depth interviews with Barranquilla residents after BRT deployment, Santana Palacios et al. (2020) noted that participants who used trunk lines for a large share of their trip reported that BRT provided travel time savings; however, BRT implementation may have increased travel duration for some residents, particularly for those who rely on feeder services. These users tend to live in peripheral neighborhoods and are often poor. Despite the insightful findings, their empirical evidence focuses on a limited number of respondents and only one city.

Our research draws from a large body of research on BRT and transport equity and departs from previous scholarship by employing a comparative research design. In this paper, we first describe the changes in commute times experienced by residents in Cape Town and Barranquilla with BRT deployment, then draw from multiple sources to untangle the possible factors driving the distribution of commute time savings enabled by BRT between different population groups. Finally, by juxtaposing the results from each city, our research harnesses the benefits of comparison, which according to Collier (1993, p. 105), "is a fundamental tool of analysis [that] sharpens our power of description and plays a central role in concept-formation by bringing into focus suggestive similarities and contrasts among cases." Moreover, and as Goodrick (2019) noted, comparative analyses produce knowledge that is easier to generalize than when drawing inferences from a single case.

\section{$3 \quad$ Research design}

We used a comparative mixed-methods research design consisting of quantitative data analyses of original survey data collected in Cape Town and Barranquilla, followed by data triangulation with secondary sources to interpret the results from our survey analysis in both cities. Below we explain the rationale behind selecting Barranquilla and Cape Town for our comparative analysis and offer a summary of our sampling methodology, data collection instrument, recruitment strategy, and survey data analysis method. We close this section with some insights from our data triangulation exercise that then we expand in the conclusions and policy recommendations section. 


\subsection{Cases selection rationale}

We chose to compare Barranquilla and Cape Town's BRT systems for five reasons. First, BRT opened at about the same time in both cities (between 2010 and 2011), making them good candidates for our comparative analysis. Second, both cities invested in BRT as part of a broader policy intended to replace private transit routes gradually. Third, both cities adopted the same feeder-trunk route configuration following Bogotâs BRT success, with some variations, such as adding some direct-route services to their route supply. Fourth, both cities are entrenched in inequality and similar spatial segregation patternsalong racial lines in Cape Town and along economic lines in Barranquilla-allowing us to draw more congruent cross-case conclusions. Finally, data collection was feasible in both cities as we were able to identify local partners to aid with logistical issues in conducting fieldwork.

Despite the similarities between the two cases, they differ on at least three fronts, which we addressed during our triangulation process to help explain our survey results. First, Cape Town's urban extent is three times as large as Barranquilla's. Second, Cape Town's BRT trunk corridors and direct-route services are significantly longer than Barranquilla's. Third, the trunk-to-feeder length ratio is substantially greater in Cape Town than in Barranquilla. The following subsections summarize these characteristics and provide some background information on each BRT system.

\section{Cape Town and its BRT, "MyCiti”}

With a population of 3.7 million inhabitants, Cape Town is characterized by relatively low density, with about 1,500 inhabitants per square kilometer and very high levels of racial and economic segregation (Christopher, 2001; Stats SA, 2011). As is the case with many cities in the Global South, economically disadvantaged populations, primarily Black Africans, are concentrated in peripherally located areas (locally referred to as townships), far from the city business district and other employment clusters (Figure 1). Cape Town's transport system includes a mix of BRT (called MyCiti), commuter rail lines, loosely regulated minibus taxis, and regulated but privately-operated conventional buses (Golden Arrow).

The city's 2006 development plan called for transport interventions that would reduce average peak-period commute time for public transport users from a baseline of 45 minutes in 2007 to 35 minutes by 2012 (City of Cape Town, 2007). With this goal in mind, Cape Town's BRT plan included provisions such as "[providing] basic mobility for the economically disadvantaged but also a competitive alternative to the private vehicle with reference to convenience, comfort, network coverage, and geographical accessibility" (City of Cape Town, 2009, p. 15).

Cape Town's BRT network is shown in Figure 1. The first service opened in 2010 with a limited route for the FIFA World Cup. Regular trunk services began in 2011 along a corridor that connected the city center with the northern part of the city, along with several feeder routes. In 2015, the second phase of the project opened to the public, connecting the outlying townships of Mitchell's Plain and Khayelitsha with the city's business central district two direct-service (or express) routes. These express routes use the bus lane on the $\mathrm{N} 2$ highway to surpass traffic congestion on mixed traffic lanes during peak hours. As of 2015, MyCiti had a network consisting of approximately 133 kilometers of trunk routes, 318 feeders, and 126 direct-routes services (in which buses with doors on both sides enter and leave trunk corridors). 


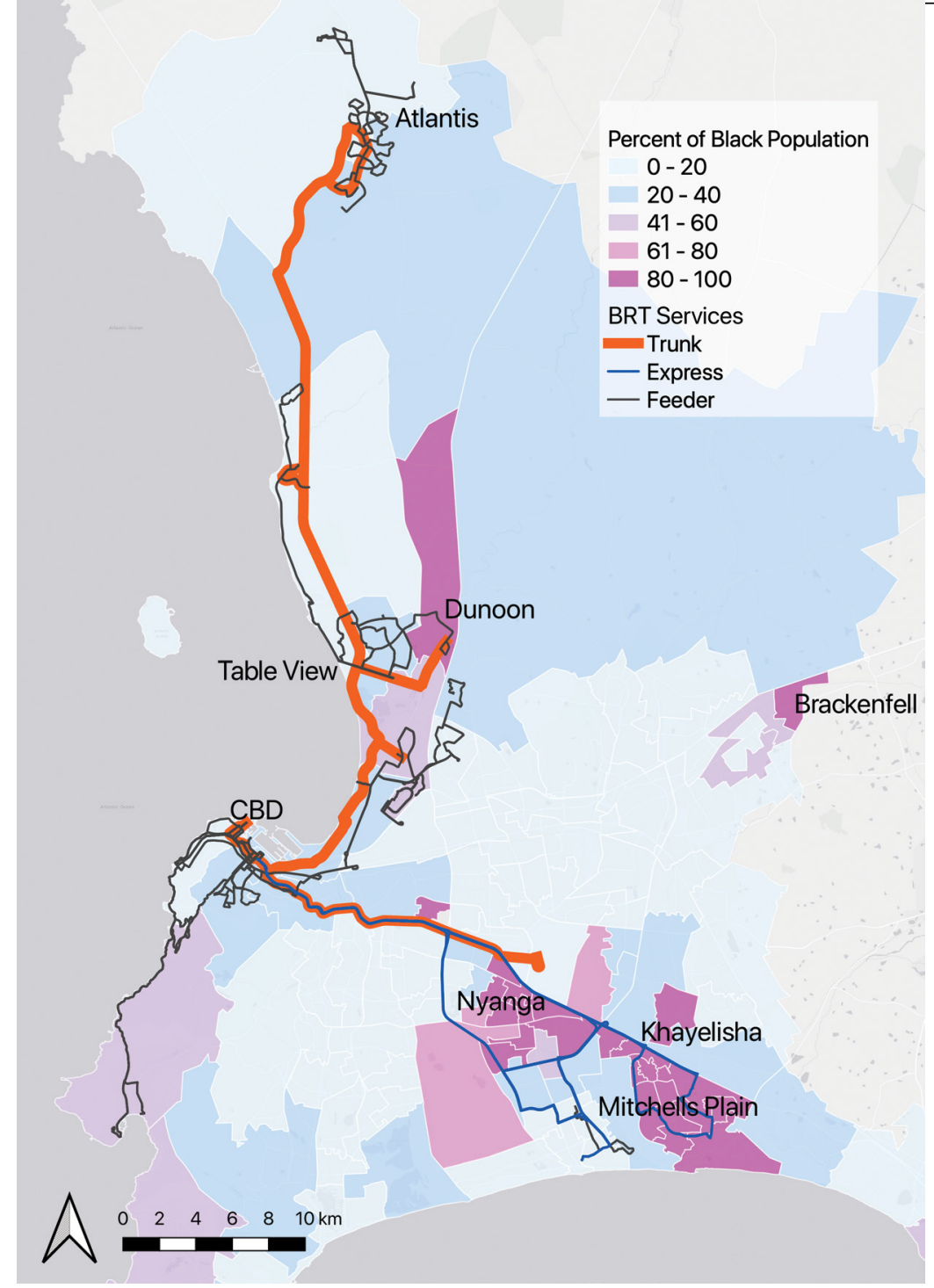

Figure 1. Population distribution by race in Cape Town and BRT network

Source: Own elaboration with data provided by MyCiti and the 2011 South African Census. Note: Phase 1 of the MyCiti network connects the Cape Town city center to neighborhoods and townships to the north. The MyCiti N2 Express (Phase 2) connects the city center to the eastern townships.

\section{Barranquilla and its BRT, "Transmetro"”}

With a population of approximately 2.4 million in 2012, Barranquilla is considered a mid-sized metropolitan area. Barranquilla is characterized by relatively high density—on average, about 7,900 inhabitants per square kilometers - with very high levels of informality and socioeconomic segregation (Figueroa, 2010; Mertins, 2007). Like many urban areas in the Global South, economically disadvantaged populations reside in peripheral neighborhoods (Figure 2). As of 2015, Barranquilla's transit supply consisted of a mix of BRT trunk and feeder services and private transit services provided by loosely regulated private transit buses and unregulated paratransit services provided mostly in motorcycle-taxis and bicycle taxis.

Barranquilla's BRT, Transmetro, opened to the public in 2010 (the same year Cape Town's BRT 
opened to the public). With approximately 14 kilometers of exclusive trunk corridors and 190 kilometers of feeder routes, and one direct-route service, Transmetro connects the municipality of Soledad and southern Barranquilla's neighborhoods with the city center and some neighborhoods in the city of Puerto Colombia to the north (Figure 2). Soledad is the second biggest city in the Barranquilla metropolitan area. Hereafter, we refer to the three cities combined as "Barranquilla."

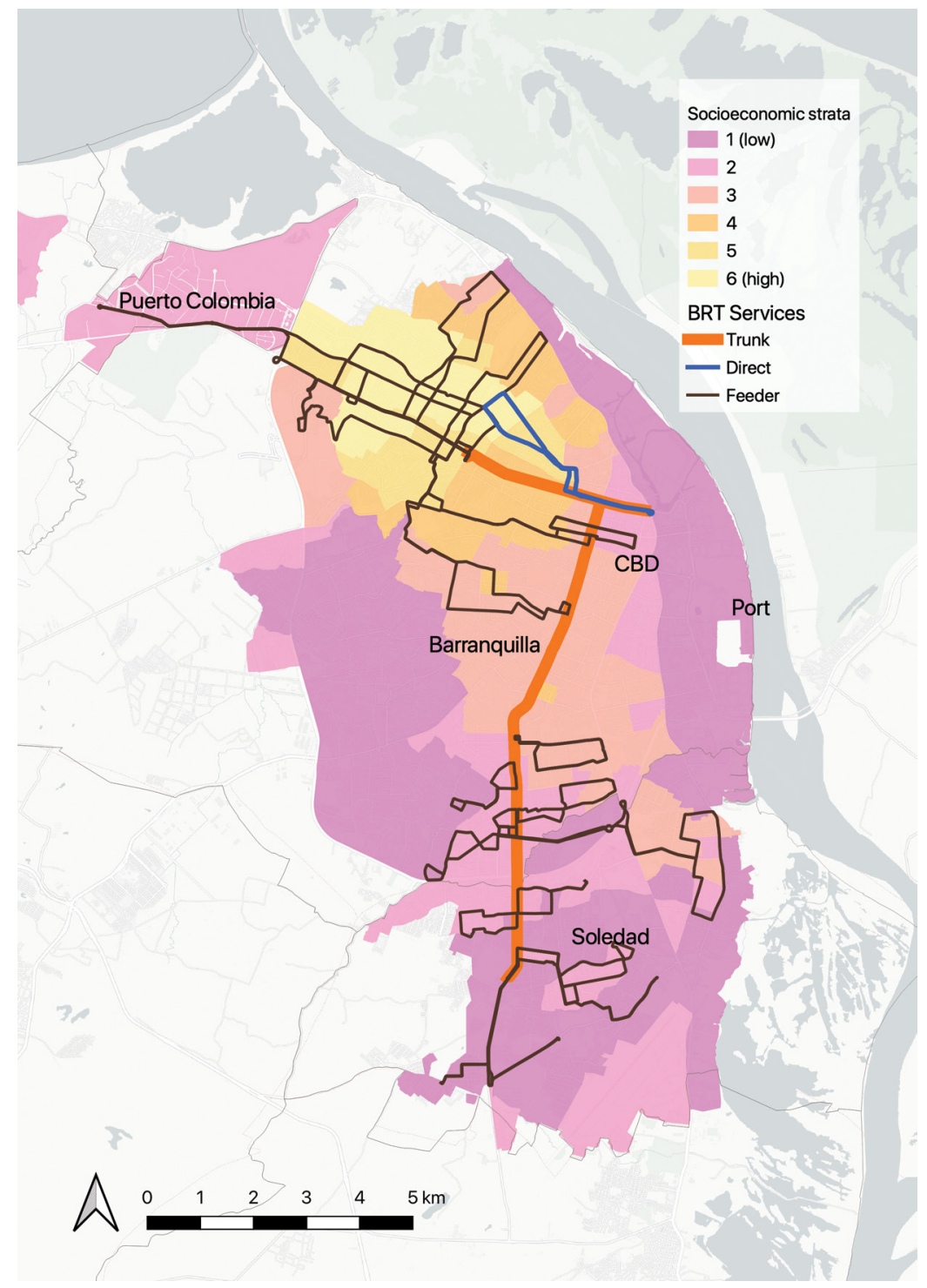

Figure 2. Barranquilla’s socioeconomic strata distribution and BRT network

Source: Own elaboration with data provided by Universidad del Norte. Note: Phase 1 of the Transmetro network connects the Barranquilla city center to neighborhoods to the north and south of the city and with the municipality of Soledad

Barranquilla’s BRT was designed to provide a safe, efficient, rapid, and convenient transport alternative to the existing inefficient and loosely regulated private transit services locally referred to as conventional transport or buses (DNP, 2004). As part of the BRT deployment plan, authorities removed some of the pre-existing conventional bus routes operating on areas Transmetro covers to reduce competition and excess supply along principal corridors. Private transit buses still operate in Barranquilla, covering 
origin and destination areas not covered by the BRT. Many use the same two major arterial roads where the two major BRT trunk corridors are placed.

\subsection{Sampling, data collection instrument, and recruitment strategy}

Our sampling framework consisted of adults living in Cape Town and Barranquilla for at least five years. The five-year timeframe requirement guaranteed that we only included individuals who lived in each city before and after the introduction of BRT. We collected responses from a total of 1,165 respondents in Barranquilla and 1,115 in Cape Town. After excluding cases with no reported travel time in 2010 or 2015 or missing information regarding home or work address in 2010 or 2015, the number of cases was reduced to 1,059 in Barranquilla and 1,023 in Cape Town. Thus, the target population comprised those who lived in each city and traveled by any mode, with an emphasis on BRT users.

Our data collection instrument consisted of a retrospective intercept survey, administered in Cape Town during October and November 2015 and in Barranquilla during November 2015. We asked respondents to describe their usual trip to and from their place of work or study in 2010 (just before BRT opened to the public) and in 2015. The survey questionnaire also included questions regarding their pre- and post-BRT home and work locations (2010 and 2015, respectively) and their demographic and socioeconomic characteristics. Our five-year sampling framework was appropriate for this retrospective survey since participants could reasonably remember their recurrent travel behavior patterns before BRT opened to the public.

We based our research design on a retrospective intercept survey for three reasons. First, and perhaps most importantly, on rare occasions, cities have available pre-BRT and post-BRT data that allows researchers to examine the effects of such investments on travel. In our case, we opted for a retrospective survey since in both cases BRT was already in place. Had we selected cities where BRT was about to be deployed to conduct a longitudinal analysis, it would have required not only significantly more financial resources, which can make research prohibitively expensive. It would also have extended our research timeframe since planning and building these projects can take several years (if built at all). Additionally, researchers avoid panel attrition by conducting retrospective surveys, commonly found in longitudinal studies (Mayer, 2007). These are significant advantages for assessing potential outcomes from BRT implementation in the context of lack of secondary data and lengthy infrastructure planning and construction processes.

Once in the field, potential survey respondents were recruited following a non-probabilistic convenience sampling technique. Intercept sites in different areas of each city were carefully selected to elicit responses from respondents of diverse ages, occupations, and socioeconomic and demographic backgrounds (Figures 3 and 4). Within these areas, we selected transit hubs that, based on our observations, have a high volume of travelers - particularly BRT and private transit users. We included shopping centers and markets to capture non-transit users. In Barranquilla, we also included public parks, small neighborhood stores, and universities. 


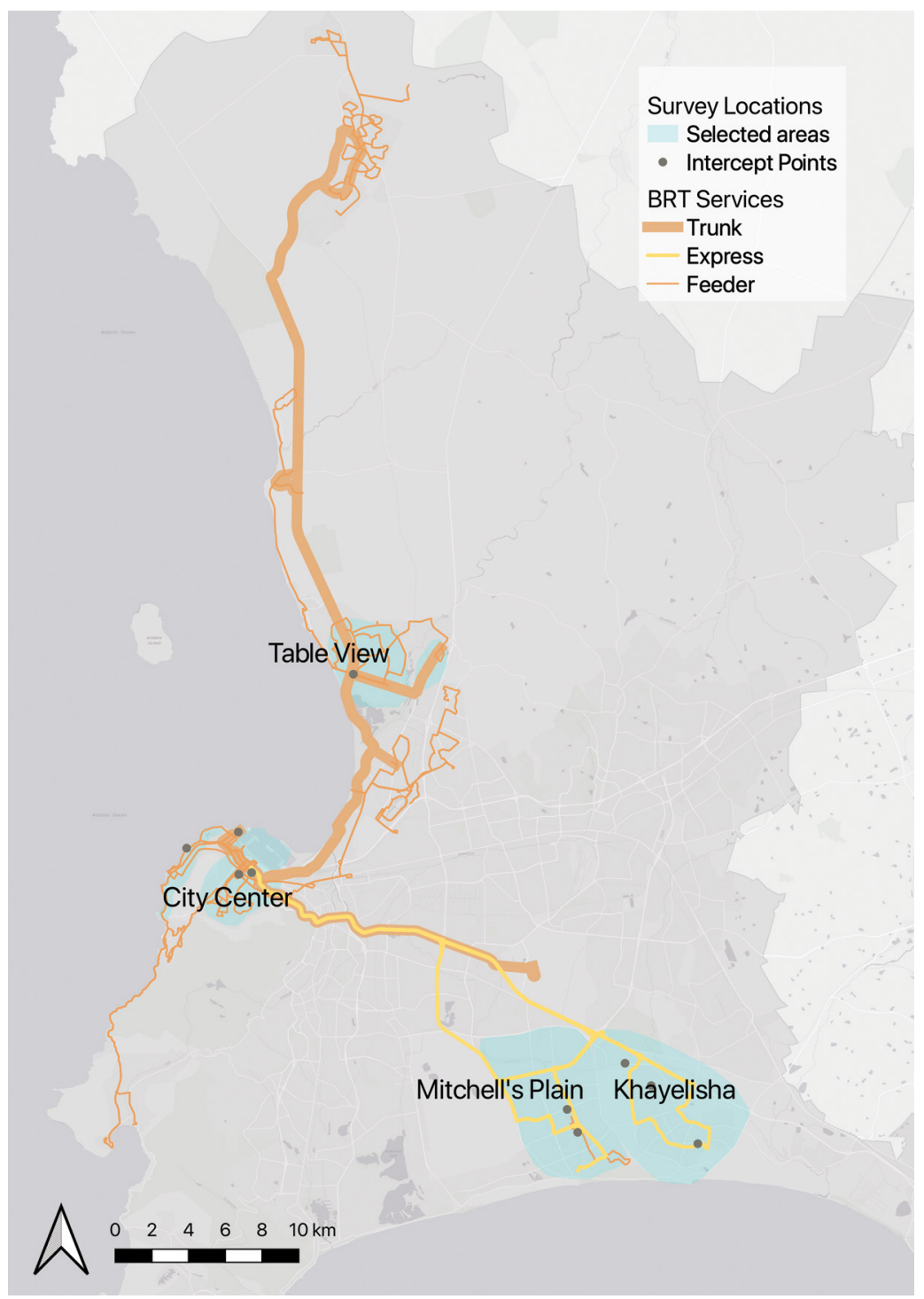

Figure 3. Cape Town survey sites

Source: Own elaboration with data provided by MyCiti and survey metadata 


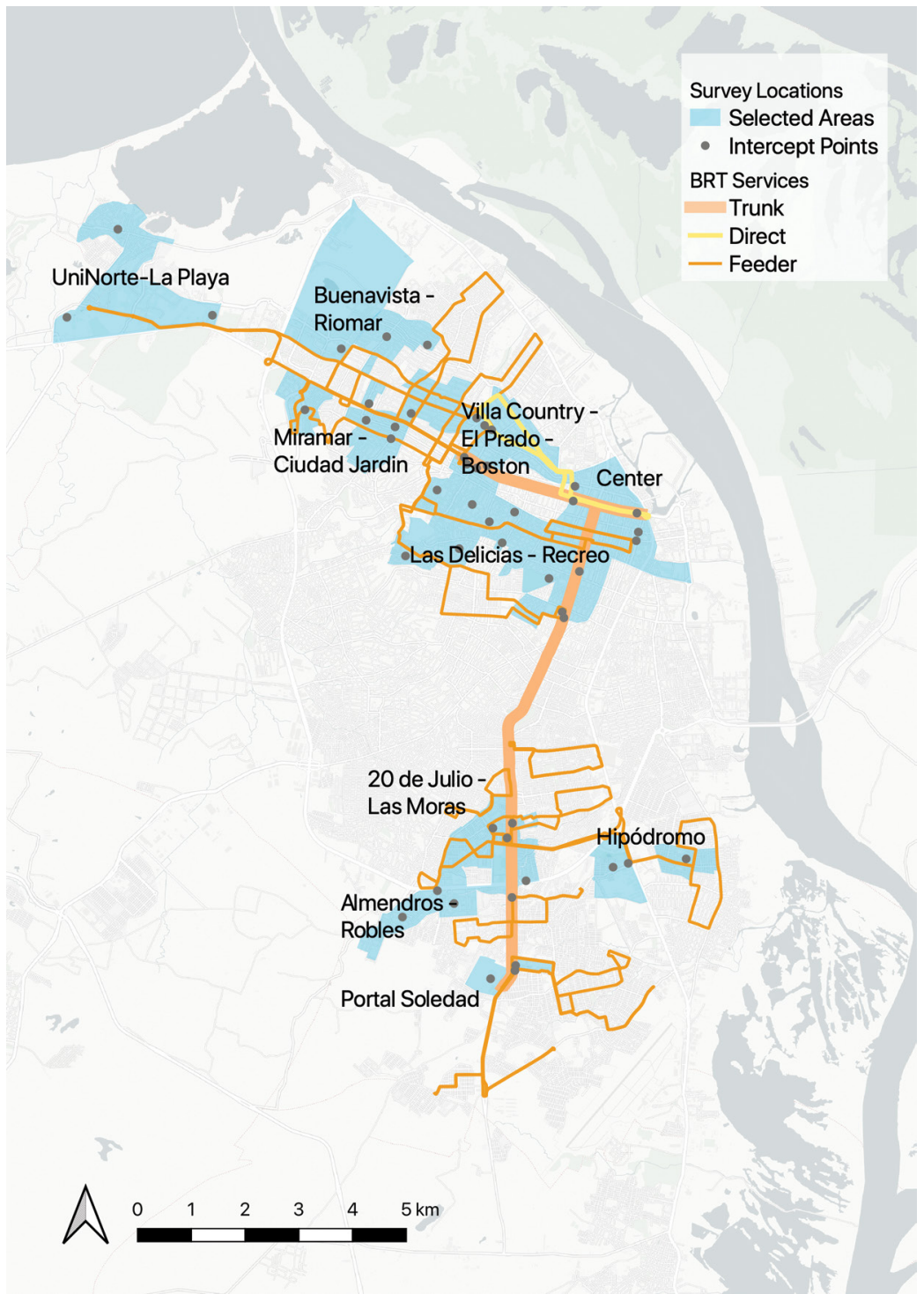

Figure 4. Barranquilla survey sites

Source: Own elaboration with data provided by Transmetro S.A. and survey metadata

\subsection{Data analysis method}

Based on the belief that BRT delivers equitable outcomes in the Global South, our research was guided by the following three hypotheses, which we tested independently: (1) on average, residents reduced their commute times after BRT was deployed in both cities—a trend that is primarily driven by residents switching from public (and private) transit to BRT; (2) BRT users reduced their commute time regardless of whether they had to transfer, although time savings are somewhat greater for BRT users who transfer since they are most likely to travel for longer distances on trunk corridors, and (3) disadvantaged BRT users experienced slightly greater commute time savings than non-disadvantaged BRT users.

To test these hypotheses, we estimated the differences in mean commute times for different groups of residents in each city. We compared the results following a multi-stage and decomposition process. We started by examining city-wide trends and trends for those who did not relocate their residence and workplace between 2010 and 2015 (whom we refer to as "non-movers"). We also classified participants 
by transport mode used in 2010, noting which individuals switched to BRT in 2015. In a subsequent step, we subclassified non-movers by (a) their need to transfer and (b) their socioeconomic status in each city, and we compared commute time changes within those categories.

Because we compared the commute times of the same group of subjects before and after BRT deployment, and because no other major changes in transport infrastructure occurred from 2010-2015, our research indicates that average commute time changes are associated with BRT deployment. All of our comparisons are accompanied by tests of significance to assess whether the observed differences in means are not a result of random chance. We assumed non-equal variances for all the paired t-tests conducted and only refer to statistically significant changes at a 90 percent confidence level unless stated otherwise. We also assumed non-mover respondents selected the mode that minimized commute times. Therefore, for cases where respondents reported a change in commute time, we assumed residents chose the fastest mode they could afford.

We used different proxies for socioeconomic status in each city. In Cape Town, we used as a proxy survey respondents' race, based on the fact that the racial stratification which was institutionalized during apartheid is, unfortunately, still in effect today (Seekings \& Nattrass, 2005). Within this sociodemographic structure, White residents are the most advantaged, followed by mixed-race groups and Black African residents. Respondents in Barranquilla were classified using the Colombian strata classification, which quantifies socioeconomic status on a scale from one to six, with six being the highest (DANE, 2015). We grouped survey participants from Barranquilla into three categories: low (1 and 2), middle (3 and 4), and high strata (5 and 6). We considered using income for segmenting the population subject for our equity analyses; however, non-response rates for this question were unacceptably high (42 non-response in Cape Town and 23 percent in Barranquilla).

\subsection{Limitations}

Despite the merits of our research design, our paper may also have some limitations. First, the nature of intercept surveys means data may present some biases. To reduce self-selection and response biases, we recruited a large number and a wide variety of survey respondents by intercepting them in multiple locations and different times of the day during a period that extended for several weeks. Thus, locations and times of day were chosen to achieve a diverse sample of various economic and demographic backgrounds.

Notwithstanding these attempts to reduce potential biases, our sample may have underrepresented some groups (Table 1). In Cape Town, White residents and car users seem to be underrepresented in our sample compared with 2010 census figures (Table 1). Our survey may also have underrepresented high-income residents and seniors in Barranquilla. However, the question of representation is difficult to assess due to a lack of reliable data. For example, the most recently available census in Colombia was conducted approximately a decade ago, which prevented us from comparing our sample with population figures. Moreover, researchers have consistently found difficulties in surveying certain population groups, for example, White residents in South Africa (Seekings \& Nattrass, 2005). Underrepresentation of a few population groups deterred us from dividing the sample into smaller subgroups for additional comparisons.

Finally, it is possible that survey respondents perceived their travel times to be longer than they are, particularly for those who transfer from one route to another. The reason is that transit users tend to perceive walking and waiting times as more onerous than in-vehicle travel times (Iseki \& Taylor, 2009; Wardman, 2004). Despite this limitation, using self-reported data may still provide valuable information not captured in other published work, such as those relying on transit network analyses. Standardized transit network data represent an invaluable resource that sheds some light on the potential changes in commute times and employment accessibility enabled by transit improvements when combined with 
spatial data analysis techniques. However, standardized transit data is seldom available in Global South cities investing in BRT like Cape Town and Barranquilla.

\section{$4 \quad$ Findings and discussion}

\subsection{Sample characteristics and descriptive statistics}

Our data collection process resulted in a large and diverse sample in both cities and reflected population's demographics reasonably well (Table 1). The Barranquilla sample roughly matches the city's overall population distribution, although it skews younger than the general population estimates projected using the 2005 census. Similarly, Cape Town respondents are on average younger than the overall population. According to census figures, our sample in Cape Town comprises a larger proportion of Black residents and mixed-race respondents than the general population. Whether these differences may affect our results is discussed in the Research Design section.

Table 1. Demographics

\begin{tabular}{|c|c|c|c|c|}
\hline \multirow{2}{*}{ Variable } & \multirow{2}{*}{ Category } & \multicolumn{2}{|c|}{ Our Survey } & \multirow{2}{*}{ Census data } \\
\hline & & All respondents & Non-movers & \\
\hline \multicolumn{5}{|c|}{ Cape Town survey $(n=1,023)$} \\
\hline \multirow{3}{*}{ Sex } & Female & 58.8 & 61.5 & 51 \\
\hline & Male & 39.9 & 37.4 & 49 \\
\hline & No response & 1.3 & 1.1 & - \\
\hline \multirow{4}{*}{ Age (years) } & $20-34$ & 50.4 & 39.3 & 44.3 \\
\hline & $35-59$ & 47.2 & 57.1 & 43.1 \\
\hline & 60 or more & 1.1 & 1.5 & 12.6 \\
\hline & No response & 1.3 & 2.1 & - \\
\hline \multirow{5}{*}{ Race } & Black & 59.3 & 68.0 & 38.6 \\
\hline & Mixed Race & 28.6 & 21.7 & 42.4 \\
\hline & Indian/Asian & 1.2 & 0.5 & 1.4 \\
\hline & White & 6.6 & 5.5 & 15.7 \\
\hline & No response & 4.2 & 4.4 & - \\
\hline \multicolumn{5}{|c|}{ Barranquilla survey $(n=1,059)$} \\
\hline \multirow{3}{*}{ Sex } & Female & 49.8 & 46.6 & 51.2 \\
\hline & Male & 49.3 & 52.8 & 48.8 \\
\hline & No response & 0.9 & 0.6 & - \\
\hline \multirow{4}{*}{ Age (years) } & $17-25$ & 30.6 & 43.4 & 21.8 \\
\hline & $26-54$ & 61.6 & 51.7 & 56.7 \\
\hline & 55 or more & 6.8 & 4.5 & 21.5 \\
\hline & No response & 1.0 & 0.3 & - \\
\hline \multirow{4}{*}{$\begin{array}{l}\text { Socioeconomic Strata } \\
(1-6)\end{array}$} & Low $1-2$ & 57.5 & 56.7 & 66.4 \\
\hline & Medium 3-4 & 35.8 & 37.1 & 26.8 \\
\hline & High 5-6 & 6.4 & 5.7 & 6.8 \\
\hline & No response & 0.3 & 0.5 & - \\
\hline
\end{tabular}

Sources: Census data from Barranquilla correspond to our calculations based on population projections to 2015 published by DANE (2019) and socioeconomic strata classification as of 2014 published by Camara de Comercio de Barranquilla (2015). Data for Cape Town come from the 2011 South African Census (Stats SA, 2011). 
Average commute times for all respondents and those who did not move residence or job location between 2010 and 2015 are presented in Table 2. Non-movers represent 45 percent of the sample in Barranquilla and 60 percent of the sample in Cape Town. Descriptive statistics of commute time changes reveal a diverging trend between the two cities, which we examine in-depth in the following sections.

Table 2. Descriptive statistics of commute time (in minutes)

\begin{tabular}{|c|c|c|c|c|c|c|}
\hline Groups & Year & Mean & Median & Std Dev & Min & $\operatorname{Max}$ \\
\hline \multicolumn{7}{|l|}{ Cape Town } \\
\hline \multirow{3}{*}{ All $(n=1,023)$} & $\begin{array}{l}2010 \text { (before } \\
\text { BRT) }\end{array}$ & 47.0 & 45 & 28.7 & 0 & 180 \\
\hline & $\begin{array}{l}2015 \text { (after } \\
\text { BRT) }\end{array}$ & 45.5 & 45 & 22.1 & 4 & 150 \\
\hline & change & -1.5 & 0 & 27.8 & -95 & 105 \\
\hline \multirow{3}{*}{$\begin{array}{l}\text { Non-movers } \\
(\mathrm{n}=618)\end{array}$} & $\begin{array}{l}2010 \text { (before } \\
\text { BRT) }\end{array}$ & 52.3 & 45 & 29.1 & 10 & 180 \\
\hline & $\begin{array}{l}2015 \text { (after } \\
\text { BRT) }\end{array}$ & 46.4 & 45 & 22.1 & 10 & 150 \\
\hline & change & -5.9 & 0 & 25.1 & -95 & 105 \\
\hline \multicolumn{7}{|l|}{ Barranquilla } \\
\hline \multirow{3}{*}{ All $(n=1,059)^{b}$} & $\begin{array}{l}2010 \text { (before } \\
\text { BRT) }\end{array}$ & 33.6 & 30 & 20.7 & 3 & 125 \\
\hline & $\begin{array}{l}2015 \text { (after } \\
\text { BRT) }\end{array}$ & 36.8 & 30 & 22.1 & 2 & 150 \\
\hline & change & 3.2 & 0 & 23.6 & -80 & 105 \\
\hline \multirow{3}{*}{$\begin{array}{l}\text { Non-movers } \\
(\mathrm{n}=479)\end{array}$} & $\begin{array}{l}2010 \text { (before } \\
\text { BRT) }\end{array}$ & 34.5 & 30 & 20.7 & 3 & 125 \\
\hline & $\begin{array}{l}2015 \text { (after } \\
\text { BRT) }\end{array}$ & 34.9 & 30 & 20.6 & 2 & 120 \\
\hline & change & 0.4 & 0 & 15.7 & -75 & 75 \\
\hline
\end{tabular}

\subsection{How did commute time change city-wide after BRT implementation among non-movers?}

As we expected, our analysis of non-movers suggests that, as a group, those who shifted mode reduced their commute time in both cities (Table 3). In Cape Town, commute time savings were, to some extent, driven by a remarkable reduction in commute times from those who shifted from slow public transit buses (Golden Arrow) and commuter trains to BRT. These users saved an average of 18 and 11 minutes, respectively. Even more remarkable is the commute time reduction from those who shifted from train lines and public transit bus routes to minibus taxis, who saved an average of 35 and 21 minutes, respectively. It is worth noting that minibus taxis' services seem not to have improved, at least in terms of speed, after BRT deployment - a claim that is supported by the fact that those who used minibus taxis in 2010 and 2015 experienced, on average, a slight increase in travel time.

Nevertheless, and contrary to our expectations, we found no evidence suggesting that the group of non-movers who shifted to BRT in Barranquilla reduced their overall commute time (Table 3). Nor did we find evidence suggesting that those who shifted from private transit buses to BRT (which account 
for 96 percent of all who shifted mode) reduced their commute times as a group. Our Barranquilla analysis also suggests that commute time changes are driven by residents shifting from private transit to motorcycles. Since our sample only captures nine individuals that shifted from bus to motorcycle in Barranquilla, this finding is only indicative of a possible trend, consistent with empirical evidence presented by Rodríguez, Santana Palacios, and Pardo (2015) and Hagen, Pardo, and Valente (2016).

Table 3. Commute time change by previous mode (non-movers) ${ }^{1}$

\begin{tabular}{llcccc}
\hline $\begin{array}{l}\text { Main Mode in 2015 (after } \\
\text { BRT) }\end{array}$ & $\begin{array}{l}\text { Main Mode in 2010 } \\
\text { (before BRT) }\end{array}$ & Freq & $\begin{array}{c}\text { Mean commute time } \\
(\mathbf{m i n})\end{array}$ & $\begin{array}{c}\text { Mean change in } \\
\text { commute time } \\
(\mathbf{m i n})\end{array}$ \\
\hline Cape Town & Car as driver & $\mathbf{2 0 1 0}$ & $\mathbf{2 0 1 5}$ & \\
\hline & Bus (Golden Arrow) & 33 & 44.2 & 49.5 & 5.3 \\
Used BRT in 2015 & Minibus taxi & 117 & 73.6 & 55.6 & $-18.0^{* *}$ \\
& Train & 99 & 44.4 & 49.3 & $4.8^{*}$ \\
& Bus (Golden Arrow) & 31 & 74.7 & 63.7 & $-11.0^{*}$ \\
\hline Used minibus taxi in 2015 & Minibus taxi & 56 & 64.5 & 43.5 & $-21.0^{* * *}$ \\
& Train & 130 & 35.5 & 36.7 & $1.2^{* *}$ \\
\hline Barranquilla & & 34 & 74.3 & 38.8 & $-35.4^{* * *}$ \\
\hline BRT users in 2015 & Bus & & & & \\
\hline \multirow{2}{*}{ Motorcycle users in 2015 } & Bus & 132 & 46.6 & 44.6 & -2.1 \\
\hline
\end{tabular}

${ }^{*} \boldsymbol{p} \leq 0.10,{ }^{* *} \boldsymbol{p} \leq 0.05,{ }^{* * *} \boldsymbol{p} \leq 0.01$.

So far, our city-wide results are mixed, as with most findings from the body of literature examining BRT travel outcomes. However, our comparative research design and data collection instrument allowed us to uncover some notable trends that may help explain how and why BRT affects average commute times differently in these two cities. Additionally, although we found no evidence of commute time savings among non-mover BRT users in Barranquilla, it is still possible that some who rely on trunk services experienced gains, as previous studies suggest.

\subsection{How did transfers affect commute times?}

Because both cities modeled their BRT after Bogotás trunk-feeder distributor model, it is essential to understand the extent to which the number of transfers increased and test whether an increase in transfers may have contributed to increases in overall commute times. In this context, we hypothesized that BRT users reduced their commute time regardless of whether they had to transfer, although savings may be greater for BRT users who do not transfer. Testing these two hypotheses in both cities was fundamental for determining under which conditions BRT may contribute to narrow commute time gaps in urban areas.

${ }^{1}$ Following principles of visualization simplicity, only main transport modes with ten or more observations or which mean difference in commute times are statistically significant are reported. From those who shifted to BRT in Barranquilla, only one used car, one motorcycle, one walked, and three used taxi in 2010, representing less than four percent of all who shifted to BRT in our sample. No motorcycle users were intercepted in Cape Town, neither in our survey nor in the official 2014 Cape Town Household Travel Survey. 
Our sample results indicate transfers increased considerably after BRT implementation in both cities. In Barranquilla in 2010, eight percent of all non-movers had to transfer between vehicles to access their final destination; this figure tripled in 2015, once BRT was in place. Similarly, the proportion of all non-movers who had to transfer in Cape Town increased from 18 percent in 2010 to 27 percent in 2015, representing a notable yet smaller increase than in Barranquilla.

Looking more closely at our data, we found that among those non-movers who used BRT in 2015 in Cape Town, 40 percent had to transfer, whereas, in 2010, only 23 percent of this subgroup did. Similarly, we found that among the same subset in Barranquilla, 64 percent had to transfer in 2015, whereas in 2010, only 16 percent did. The increase in transfers for the non-movers surveyed in both cities may be attributed to BRT since no other major change in the transit system was implemented within this time frame.

Despite evidence that BRT induced a notable increase in the proportion of transfers in both cities, whether such a surge was associated with longer commute times is another question. Our survey data from Cape Town suggests that, on average non-mover BRT users reduced their overall commute time, regardless of whether they had to transfer (Table 4). In contrast, our survey data from Barranquilla suggests that only BRT users who do not transfer experienced commute time savings. This apparent contradiction raises two fundamental questions we answer in the following sections: (1) What are the potential causes of these divergences? (2) Do these diverging patterns also emerge when comparing commute time changes of different population groups?

Table 4. Commute time change (in minutes) for BRT users who transfer and do not transfer (non-movers)

\begin{tabular}{lllll}
\hline \multirow{2}{*}{ Group } & Freq. & \multicolumn{2}{c}{ Mean commute time } & Mean change in commute time \\
& & $\mathbf{2 0 1 0}$ & $\mathbf{2 0 1 5}$ & \\
\hline Cape Town & & & & \\
\hline BRT users who transfer & 119 & 62.9 & 58.0 & $-4.9^{*}$ \\
BRT users who do not transfer & 159 & 56.9 & 50.7 & $-6.2^{* *}$ \\
\hline Barranquilla & & & & 0.8 \\
\hline BRT users who transfer & 89 & 49.6 & 50.4 & $-7.0^{* *}$ \\
BRT users who do not transfer & 49 & 40.3 & 33.3 & \\
\hline
\end{tabular}

${ }^{*} \boldsymbol{p} \leq 0.10,{ }^{* *} \boldsymbol{p} \leq 0.05,{ }^{* * *} \boldsymbol{p} \leq 0.01$

\subsection{How did changes in commute time differ between socioeconomic population groups?}

Since those who live in peripheral areas served by feeder services are most likely to transfer, one plausible outcome is that disadvantaged groups, who often locate in these areas, did not experience the same commute time savings as their non-disadvantaged counterparts. However, it is still possible that disadvantaged population groups experienced similar, if not more, commute time savings. First, not all economically disadvantaged BRT users reported a significant increase in the number of transfers, and some non-disadvantaged groups also experienced a rise in the number of transfers. Second, even if transfers increased more for disadvantaged groups, those whose significant amount of their commute rely on BRT trunk services may still experience large commute time reductions. ${ }^{2}$

2 While our survey did not ask for the details of their commutes besides travel times and transfers, this information is still useful in providing an overall understanding of what socioeconomic status groups benefit the most from BRT deployment. 
As with the results of our comparative analysis on transfers, and in line with the mounting body of literature that examines BRT on equity grounds, our results measuring changes in commute times by socioeconomic status are mixed (Table 5). Our results from Cape Town indicate that the gap in commute time between different socioeconomic status groups narrowed after BRT was deployed; in Barranquilla, however, we found no evidence suggesting that average commute times changed at any socioeconomic group level (Table 5). While non-mover Black residents who shifted to BRT in Cape Town saved seven minutes on average, we found no evidence that non-mover White residents who reported using BRT in the city reduced their commute time. ${ }^{3}$

Table 5. Commute time change by socioeconomic status

\begin{tabular}{lllccc}
\hline Group & Subgroup & Freq. & \multicolumn{2}{c}{ Mean commute time } & $\begin{array}{c}\text { Mean change in } \\
\text { commute time }\end{array}$ \\
\hline Cape Town & & & $\mathbf{2 0 1 0}$ & $\mathbf{2 0 1 5}$ & \\
\hline \multirow{2}{*}{ All respondents } & Black African & 607 & 49.9 & 45.1 & $-4.82^{* * *}$ \\
& Mixed Race & 293 & 44.7 & 48.5 & $3.85^{* *}$ \\
& White & 68 & 34.5 & 41.8 & $7.37^{* *}$ \\
Non-movers, BRT-users & Black African & 188 & 61.0 & 53.7 & $-7.37^{* * *}$ \\
& Mixed Race & 94 & 59.1 & 56.2 & -2.86 \\
\hline Barranquilla & White & 16 & 39.1 & 43.8 & 4.69 \\
\hline \multirow{3}{*}{ All respondents } & & & & 40.3 & $4.4^{* * *}$ \\
& Low (1-2) & 609 & 36.0 & 33.3 & 1.5 \\
& Medium (3-4) & 379 & 31.8 & 23.3 & 1.0 \\
Non-movers, BRT users & High (5-6) & 68 & 22.2 & 48.5 & -2.1 \\
& Low (1-2) & 93 & 50.7 & 35.9 & -1.7 \\
& Medium (3-4) & 44 & 37.6 & 25.0 & 0.0 \\
\hline
\end{tabular}

${ }^{*} \boldsymbol{p} \leq 0.10,{ }^{* *} \boldsymbol{p} \leq 0.05,{ }^{* * *} \boldsymbol{p} \leq 0.01$

It is important to note that the small number of non-economically disadvantaged residents intercepted in each city does not compromise our conclusions. The 16 White non-mover BRT users in Cape Town represent 5 percent of all non-mover BRT users in our sample. If we assume the 0.3 percent of BRT commute trips in Cape Town are conducted by White residents, our 5 percent figure suggests our sample does not underrepresent White residents who used BRT vis-à-vis other users by race. Had we intercepted a significantly greater number of high-strata residents in Barranquilla, who, as a group, reported significantly large commute time changes, it would likewise not compromise our conclusions since we found no evidence that the large share of low-strata BRT users reduced their commute time as a group. This would have still indicated that BRT did not contribute to closing the commute time gap in the city.

\footnotetext{
3 The difference in change in commute time between White and non-White residents was statistically significant (p-value $=0.098$ ).
} 


\section{$5 \quad$ Conclusions and policy implications}

How did commute time changes differ between socio-demographic status groups in Cape Town, South Africa, and Barranquilla, Colombia? Our survey data indicates that while BRT deployment did not narrow the gap in commute times between low and high socioeconomic strata groups in Barranquilla, BRT did narrow the gap in commute times between different races in Cape Town. We argue that this apparent contradiction may be in part explained by the degree to which BRT design responded to urban form and pre-BRT transit conditions, two factors which are often overlooked in academic literature and policy discussions surrounding BRT and transport equity as Venter et al. (2017) also pointed out.

A critical lesson from this research is that BRT route configuration may dictate the degree to which BRT can benefit economically disadvantaged populations. Although both cities exhibit similar urban segregation patterns, two evident characteristics in which these two metropolitan areas diverge is that they have drastically different urban extent and trunk-feeder routes' length ratios. Cape Town's urbanized area is about ten times as large as Barranquilla's and had longer arterial roads than Barranquilla before BRT started being considered. Accordingly, Cape Town's BRT exhibits considerably longer trunk corridors, with relatively shorter feeder services than Barranquillas. Therefore, it is entirely plausible that the commute time advantage provided by BRT trunk services in Barranquilla was not sufficient to compensate for the additional transfer times induced by BRT. Commute time savings in Cape Town seem to be enabled by a better-balanced feeder-trunk system and long direct (or express) routes that serve some outlying townships, where most Black residents reside. These findings also indicate that the popular feeder-trunk-distributor BRT model may not necessarily be the most appropriate alternative for mid-sized cities.

Had we relied on a single case, this conclusion, which is consistent with conjectures posed by other scholars such as Gómez-Lobo (2020) and Ferro and Behrens (2015), would not have been as compelling. Thus, our comparative research design and resulting evidence open a path for more studies that explores the apparent relationship between the distribution of commute time savings, BRT network design, and urban form. Based on this evidence, we recommend that future examinations of BRT and transport equity consider how user commute patterns, including distances traveled between and home and workplace locations, influence the degree to which BRT can deliver more equitable travel time savings.

A second important lesson from this study is that when planning to restructure transit systems through BRT, planners must account for how efficient the pre-existing transport system is, paying particular attention to attributes such as travel time and convenience. In Cape Town, the decrease in commute times between 2010 and 2015 was driven by a remarkable drop in commute times from those who shifted from slow public transit buses and trains to BRT. In contrast, in Barranquilla, we found that those who switched to BRT from private transit buses, which account for the most BRT users, did not reduce their commute times. In other words, Cape Town's pre-existing transit conditions allowed BRT much room for improvement; however, in Barranquilla, the popular feeder-trunk BRT design seemed to have fewer chances to succeed.

An emerging trend we identified is the increase in average commute time by the group of participants who moved their residence or work location during the analysis period. While examining this group in depth is out of this paper's scope, this trend deserves further examination. Many residents may have moved to locations closer to BRT trunk corridors not necessarily to reduce their commute time but rather to take advantage of the built environment improvements that often accompany BRT deployment (Rodríguez, Brisson, \& Estupińán, 2009; Rodriguez \& Vergel-Tovar, 2018). Another plausible hypothesis is that more residents place a higher value on home attributes and prices over shorter commute times (Chatman, Broaddus, \& Spevack, 2019). 
Policymakers and planners who hope that BRT will reduce commute time gaps in Global South cities must carefully consider the potential combined effects of BRT network design and urban form. Our research suggests that the BRT trunk-to-feeder length ratio plays a crucial role in determining the extent to which commute time benefits are distributed in space and points out the importance of considering other design alternatives. Striking an ideal trunk-to-feeder length balance seems to be of particular significance in cities where most economically disadvantaged populations reside in peripheral neighborhoods.

We recognize that many cities in the Global South exhibit intricate street patterns in peripheral lowincome areas of informal origins, making deploying BRT trunk corridors challenging. In the contexts of these cities, we recommend testing more feasible and less capital-intensive alternatives to overcome the physical limitations of extending BRT corridors to peripheral communities. One option is to implement bus-only lanes for feeder services to improve bus speeds and service reliability. Another complementary intervention is testing a few direct-service routes, as Cape Town did more extensively than Barranquilla. Able to serve both peripheral neighborhoods and trunk-corridor stations, direct-route services eliminate feeder-trunk transfers for those commuting from peripheral to more central locations.

Designing transit systems that are more sensitive to urban form, understood as the physical manifestation of land use planning (or lack of thereof), may result in better travel outcomes for economically disadvantaged populations and prevent residents from shifting from transit to private vehicles and increase overall transit ridership levels, as Gomez-Lobo (2020) suggests. Better public transit design choices may, in turn, increase the likelihood of cities becoming more equitable and environmentally sustainable.

\section{Acknowledgements}

Funding for this research comes from the Volvo Research and Education Foundation. We thank professors Daniel Chatman and Robert Cervero from UC Berkeley and the four anonymous reviewers for providing valuable guidance and feedback. Special thanks to professors Roger Behrens and Herrie Schalekamp from the University of Cape Town and professors Victor Cantillo and Julian Arellana from Universidad del Norte for making the survey work possible. We also thank Kelan Stoy, who helped design the survey and managed the Barranquilla survey implementation, and Federico Diaz from Barranquilla's BRT public agency for providing valuable data. Many thanks also to our surveyors, including Claire Birungi, Xoliswa Gqola, Xochiwe Jere, Mercy King'Ori, Graeme Leighton, Sakhumzi Mbulawa, Mzanya Ndibongo, Tamara Sam, Adriana Russill, Astor Andres Dominguez, Evelin Arias, Sergio Iguaran, Silvana Sinin, Yoheilein Valbuena, Edgardo Uhia Aroca, Gisell Herrera, Julio Cantero Durango, and Oswaldo Figueroa. 


\section{References}

Alpkokin, P., \& Ergun, M. (2012). Istanbul metrobüs: First intercontinental bus rapid transit. Journal of Transport Geography, 24, 58-66. https://doi.org/10.1016/j.jtrangeo.2012.05.009

Ardila-Gómez, A. (2008). Limitation of competition in and for the public transportation market in developing countries: Lessons from Latin American cities. Transportation Research Record: Journal of the Transportation Research Board, 2048, 8-15. https://doi.org/10.3141/2048-02

Bel, G., \& Holst, M. (2018). Evaluation of the impact of bus rapid transit on air pollution in Mexico City. Transport Policy, 63, 209-220. https://doi.org/10.1016/j.tranpol.2018.01.001

Cámara de Comercio de Barranquilla. (2015). Observatorio urbano local del area metropolitana de Barraquilla. Baranguilla, Columbia: Cámara de Comercio de Barranquilla.

Cervero, R. (2013). Bus rapid transit (BRT): An efficient and competitive mode of public transport (Working paper No. 2013-01). Berkeley, CA: Institute of Urban and Regional Development, University of California, Berkeley.

Cervero, R., \& Kang, C. D. (2011). Bus rapid transit impacts on land uses and land values in Seoul, Korea. Transport Policy, 18(1), 102-116. https://doi.org/10.1016/j.tranpol.2010.06.005

Chatman, D. G., Broaddus, A., \& Spevack, A. (2019). Are movers irrational? On travel patterns, housing characteristics, social interactions, and happiness before and after a move. Travel Behavior and Society, 16, 262-271. https://doi.org/10.1016/j.tbs.2018.11.004

Chatterjee, K., Chng, S., Clark, B., Davis, A., De Vos, J., Ettema, D., ... \& Reardon, L. (2020). Commuting and wellbeing: A critical overview of the literature with implications for policy and future research. Transport Reviews, 40(1), 5-34. https://doi.org/10.1080/01441647.2019.1649317

Christopher, A. J. (2001). Urban segregation in post-apartheid South Africa. Urban Studies, 38(3), 449-466. https://doi.org/10.1080/00420980120080031

City of Cape Town. (2007). Five-year plan for Cape Town-integrated development plan 2007/82011/12. Cape Town: City of Cape Town.

City of Cape Town. (2009). Integrated transport plan 2006-2011 review 2009. Cape Town: City of Cape Town.

Collier, D. (1993). The comparative method. In A. W. Finifter \& American Political Science Association (Eds.), Political science: The state of the discipline II. Washington, DC: American Political Science Association.

DANE. (2015). Estratificación socioeconómica para servicios públicos domiciliarios. Bogotá: Departamento Administrativo Nacional de Estádistica (DANE).

DANE. (2019). Proyecciones de población. Bogotá: Departamento Administrativo Nacional de Estádistica (DANE).

Delmelle, E. C., \& Casas, I. (2012). Evaluating the spatial equity of bus rapid transit-based accessibility patterns in a developing country: The case of Cali, Colombia. Transport Policy, 20, 36-46. https:// doi.org/10.1016/j.tranpol.2011.12.001

DNP. (2004). Conpes 3306. Sistema Integrado del Servicio Público Urbando de Transprote Masivo de Pasajeros del Distrito de Barranquilla y su Área Metropolitana. Bogotá: Departamento Nacional de Planeación.

Duduta, N., Adriazola, C., Hidalgo, D., Lindau, L. A., \& Jaffe, R. (2012). Understanding road safety impact of high-performance bus rapid transit and busway design features. Transportation Research Record: Journal of the Transportation Research Board, 2317(1), 8-14. https://doi.org/10.3141/231702

Ernst, J. (2005). Initiating bus rapid transit in Jakarta, Indonesia. Transportation Research Record: Journal 
of the Transportation Research Board, 1903, 20-26. https://doi.org/10.3141/1903-03

Evans, G. W., \& Wener, R. E. (2006). Rail commuting duration and passenger stress. Health Psychology, 25(3), 408-412. https://doi.org/10.1037/0278-6133.25.3.408

Ferro, P. S., \& Behrens, R. (2015). From direct to trunk-and-feeder public transport services in the Urban South: Territorial implications. Journal of Transport and Land Use, 8(1), 123-136. https://doi. org/10.5198/jtlu.2015.389

Figueroa, C. (2010). Determinantes de la informalidad laboral y el subempleo en las áreas metropolitanas de Barranquilla, Cartagena y Montería. Monterrey, Mexico: Documentos IEEC, Universidad Del Norte.

Gómez-Lobo, A. (2020). Transit reforms in intermediate cities of Colombia: An ex-post evaluation. Transportation Research Part A: Policy and Practice, 132, 349-364. https://doi.org/10.1016/j. tra.2019.11.014

Goodrick, D. (2019). Comparative case studies. In SAGE research methods foundations. New York: SAGE Publications Ltd. https://doi.org/10.4135/9781526421036849021

Gottholmseder, G., Nowotny, K., Pruckner, G. J., \& Theurl, E. (2009). Stress perception and commuting. Health Economics, 18(5), 559-576. https://doi.org/10.1002/hec.1389

Hagen, J. X., Pardo, C., \& Valente, J. B. (2016). Motivations for motorcycle use for urban travel in Latin America: A qualitative study. Transport Policy, 49, 93-104. https://doi.org/10.1016/j.tranpol.2016.04.010

Hidalgo, D., Pereira, L., Estupiñán, N., \& Jiménez, P. L. (2013). TransMilenio BRT system in Bogotá, high performance and positive impact - main results of an ex-post evaluation. Research in Transportation Economics, 39(1), 133-138. https://doi.org/10.1016/j.retrec.2012.06.005

Hidalgo, D., \& Yepes, T. (2005). Are bus rapid transit systems effective in poverty reduction? Experience of Bogotäs TransMilenio and lessons for other cities. Paper presented at the 8th annual Transportation Research Board Annual Meeting, Washington, DC.

Hilbrecht, M., Smale, B., \& Mock, S. E. (2014). Highway to health? Commute time and well-being among Canadian adults. World Leisure Journal, 56(2), 151-163. https://doi.org/10.1080/1607805 5.2014.903723

Iseki, H., \& Taylor, B. D. (2009). Not all transfers are created equal: Towards a framework relating transfer connectivity to travel behaviour. Transport Reviews, 29(6), 777-800. https://doi. org/10.1080/01441640902811304

Lleras, G. C. (2003). Bus rapid transit: Impacts on travel behavior in Bogotá, Thesis, Massachusetts Institute of Technology, Cambridge, MA. Retrieved from http://dspace.mit.edu/handle/1721.1/39777

Mayer, K. U. (2007). Retrospective longitudinal research: The German life history study. In Handbook of Longitudinal Research: Design, Measurement, and Analysis. Elsevier/Academic Press.

Mertins, G. (2007). Estudios urbanos-regionales desde el Caribe: El crecimiento moderno espacialurbano en Barranquilla: Planeación pública-oficial o manejo del sector privado. Revista Digital de Historia y Arqueología Desde El Caribe, 4(7), 113-128.

Montero, S. (2020). Leveraging Bogotá: Sustainable development, global philanthropy and the rise of urban solutionism. Urban Studies, 57(11), 2263-2281. https://doi.org/10.1177/0042098018798555

Munoz, J. C., \& Paget-Seekins, L. (2016). Restructuring public transport through bus rapid transit: An international and interdisciplinary perspective. Bristol, UK: Policy Press.

Nugroho, S. B., Fujiwara, A., \& Zhang, J. (2011). An empirical analysis of the impact of a bus rapid transit system on the concentration of secondary pollutants in the roadside areas of the TransJakarta corridors: A structural equation model and artificial neural network approach. Stochastic Environmental Research and Risk Assessment, 25(5), 655-669. https://doi.org/10.1007/s00477-011-0472-x 
Oviedo, D., Scholl, L., Innao, M., \& Pedraza, L. (2019). Do bus rapid transit systems improve accessibility to job opportunities for the poor? The case of Lima, Peru. Sustainability, 11(10), 2795. https:// doi.org/10.3390/su11102795

Pereira, R. H. M., Banister, D., Schwanen, T., \& Wessel, N. (2019). Distributional effects of transport policies on inequalities in access to opportunities in Rio de Janeiro. Journal of Transport and Land Use, 12(1), 741-764. https://doi.org/10.5198/jtlu.2019.1523

Pereira, R. H. M., Schwanen, T., \& Banister, D. (2017). Distributive justice and equity in transportation. Transport Reviews, 37(2), 170-191. https://doi.org/10.1080/01441647.2016.1257660

Rodríguez, D. A., Brisson, E. M., \& Estupiñán, N. (2009). The relationship between segment-level built environment attributes and pedestrian activity around Bogotás BRT stations. Transportation Research Part D: Transport and Environment, 14(7), 470-478. https://doi.org/10.1016/j.trd.2009.06.001

Rodríguez, D. A., Santana Palacios, M., \& Pardo, C. F. (2015). La motocicleta en América Latina: Caracterización de su uso e impactos en la movilidad en cinco ciudades de la región (Despacio). Bogotá: CAF.

Rodriguez, D. A., \& Targa, F. (2004). Value of accessibility to Bogotâs bus rapid transit system. Transport Reviews, 24(5), 587-610. https://doi.org/10.1080/0144164042000195081

Rodriguez, D. A., \& Vergel-Tovar, C. E. (2018). Urban development around bus rapid transit stops in seven cities in Latin-America. Journal of Urbanism: International Research on Placemaking and Urban Sustainability, 11(2), 175-201. https://doi.org/10.1080/17549175.2017.1372507

Rodriguez, D. A., Vergel-Tovar, E., \& Camargo, W. F. (2016). Land development impacts of BRT in a sample of stops in Quito and Bogotá. Transport Policy, 51, 4-14. https://doi.org/10.1016/j.tranpol.2015.10.002

Santana Palacios, M., Cochran, A., Bell, C., Hernández Jiménez, U., Leshner, E., Trejo Morales, F., \& Chatman, D. G. (2020). Bus rapid transit arrives in Barranquilla, Colombia: Understanding a changing landscape through residents' travel experiences. Travel Behavior and Society, 21, 131-139. https://doi.org/10.1016/j.tbs.2020.06.003

Scholl, L., Bouillon, C., Oviedo, D., Corsetto, L., Jansson, M., \& Gray, C. (2016). Urban transport and poverty: Mobility and accessibility effects of IDB-supported BRT Systems in Cali and Lima. New York: Office of Evaluation and Oversight, Inter-American Development Bank.

Seekings, J., \& Nattrass, N. (2005). Class, race, and inequality in South Africa. London, UK: Yale University Press.

Silva Ardila, D. (2020). Global policies for moving cities: The role of think tanks in the proliferation of bus rapid transit systems in Latin America and worldwide. Policy and Society, 39(1), 70-90. https:// doi.org/10.1080/14494035.2019.1699636

Stats SA. (2011). South Africa census. Pretoria, SA: Stats SA.

Vasconcellos, E. A. (2014). Urban transport environment and equity: The case for developing countries (1st ed.). London: Routledge. https://doi.org/10.4324/9781315071756

Venter, C., Jennings, G., Hidalgo, D., \& Valderrama Pineda, A. F. (2017). The equity impacts of bus rapid transit: A review of the evidence and implications for sustainable transport. International Journal of Sustainable Transportation, 12(2), 1-13. https://doi.org/10.1080/15568318.2017.1340528

Wardman, M. (2004). Public transport values of time. Transport Policy, 11(4), 363-377. https://doi. org/10.1016/j.tranpol.2004.05.001 